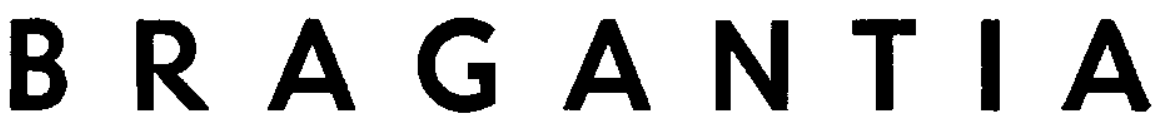

Revista Cientifica do Instituto Agronômico do Estado de São Paulo

Vol. 34 Campinas, março de 1975 N. ${ }^{\circ} 5$

\title{
ZINCO EM SOLOS DO ESTADO DE SÃO PAULO
}

\section{I - ZINCO TOTAL ( $\left.{ }^{1}\right)$}

J. M. A. S. Valadares ( : ), Seção de Pedologia, Instituto Agronômico, e R. A. Catani, Departamento de Química, E.S.A. "Luiz de Queiroz", Piracicaba, SP

\section{SINOPSE}

Determinou-se o zinco total, com ataque perclórtco-fluoridrico e espectrofotometrla de absorçio atómica, em 227 amostras de 28 perfis pertencentes a 14 unidades representativas dos solos de sto Paulo.

o material de origem foi o fator preponderante a condiclonar os teores de zinco dos solos. Os solos derivados de rochas bisicas, os mais ricos em zinco, têm os teores médios ponderados dos horizontes A de seus perfis compreendidos entre 87 e $315 \mathrm{ppm}$; os derivados de materiais aluviats e coluviats, 53 e $84 \mathrm{ppm}$; os derivados de sedimentos modernos, entre 29 e 65 ppm; os derivados do arenito Bauru, entre 16 e 30 ppm; os derivados de sedimentos modernos arenosos, entre 1 e 17 ppm, os mais pobres em rinco.

Observou-se boa correlaçio $\left(r=0,79^{* *}\right)$ entre os teores de adnco os de oxidos de terro dos solos.

\section{1 - INTRODUÇÃO}

O zinco é um dos micronutrientes essenciais para a nutrição das plantas, e a sua falta no solo afeta o desenvolvimento delas. Como säo escassas as informações referentes ao zinco em solos do Estado de São Paulo, o presente trabalho visa à obtenção de dados básicos, para o que, nesta primeira fase, se faz o levantamento do teor de zinco total em amostras de horizontes e camadas de perfis das principais unidades de solos de

(1) Parte de teac de doutoramento apresenteda pelo primelro autor, em dezembro de 1972, A Eecola Superior de Agricultura "Luiz de Queiroz". USP. Trabalho apresentado no XTV Congresso bras. Ciencia do Solo, Santa Marla, RS, do 16 a 23 de julho de 1973 . Recebido para publicacio em 27 de agosto de 1974.

(2) Com bolss de suplementaçăo do C.N.Pq. 
São Paulo. Como apenas o teor total não permite predizer a disponibilidade do zinco para as plantas, numa fase posterior será feita a determinação do teor de zinco extraído do solo por extratores apropriados, utilizados para esse fim específico.

\section{2 - MATERIAIS E METODOS}

Foram analisadas 227 amostras de 28 perfis de 14 das principais unidades de solos do Estado de São Paulo (13) (PV, Pln, Pml, TE, LRe, LRd, LE, LEa, LV, LVa, LH, R, Hi e Li bas), já caracterizados em trabalho anterior (18).

As amostras dos vários horizontes de cada perfil foram coletadas com caneca de plástico e colocadas em sacos de polietileno. Secou-se ao ar e peneirou-se em peneira de plástico com malha de $2 \mathrm{~mm}$. Para a determinação do zinco total, uma subamostra de cerca de $10 \mathrm{~g}$ foi finamente pulverizada em almofariz de ágata, até obtenção de pó impalpável.

O método utilizado na extração do zinco total foi o do ataque perclórico-fluorídrico, e baseou-se no descrito por Hanna (4). Utilizou-se $0,500 \mathrm{~g}$ de amostra finamente pulverizada, colocou-se em cápsula de porcelana e incinerou-se em mufla a $450^{\circ} \mathrm{C}$ durante 4 horas, para destruir a matéria orgânica. Em seguida, passou-se a amostra para um copo de Teflon, umedeceu-se com água desionizada e atacou-se com $2 \mathrm{ml}$ de $\mathrm{HClO}_{4}$ e $5 \mathrm{ml}$ de HF, repetindo este ataque uma ou duas vezes, conforme o digerido se tenha apresentado límpido ou turvo. Levou-se à secura, adicionaram-se $4 \mathrm{ml}$ de $\mathrm{HCl} 6 \mathrm{~N}$, cerca de $10 \mathrm{ml}$ de água desionizada, e aqueceu-se até completa dissolução do resíduo. Passou-se para balão de $50 \mathrm{ml}$ e completou-se o volume com água desionizada. Foram feitas três repetiçôes de cada amostra e conduziram-se ensaios em branco.

A determinação de zinco no extrato ácido foi feita por espectrofotometria de absorção atômica (1), com aparelho Perkin-Elmer, mod. 290B, utilizando chama de ar-acetileno. Os padróes de zinco, os quais continham $0,1,5$ e 3,0 ppm desse elemento, foram preparados a partir de uma solução intermediária de $30 \mathrm{ppm}$. A solução-estoque, de $1000 \mathrm{ppm}$, foi obtida dissolvendo-se 1,000 de zinco metálico em $\mathrm{HC} 1$ e completando o volume a 1 litro com água desionizada.

Os teores ponderados dos horizontes foram obtidos somando-se os produtos dos teores dos sub-horizontes pelas respectivas espessuras e dividindo-se essa soma pela espessura do horizonte.

\section{3 - RESULTADOS E DISCUSSAO}

Os resultados obtidos constam do quadro 1 . Os teores de zinco total dos solos analisados são semelhantes aos obtidos em solos dos USA (6, 
16, 17, 22), da URSS $(7,20,23)$, do Paquistão (21), da India $(9,11)$, da União Sul-africana (14), da Austrália (10), do Brasil (12), e inferiores aos de alguns solos de Madagascar (5) e de Angola (3).

$O$ material de origem foi o fator preponderante no condicionamento dos teores de zinco total dos solos, o que é evidenciado pelo agrupamento em função do material de origem, apresentado no quadro 1 . Os solos derivados de rochas básicas apresentaram os teores mais elevados de zinco total, fato já observado por outros autores $(5,20)$. A maior riqueza em zinco, dos solos derivados de rochas básicas, deve-se ao fato de essas rochas constituírem material de origem mais rico em zinco que os demais (20). Pelos resultados obtidos, pode-se observar que, na terra roxa estruturada e litossolo fase substrato basalto, os teores de zinco nos solos são superiores aos das rochas que lhes deram origem, fato já observado por Oertel (10), em solos derivados de basalto, na Austrália.

$\mathrm{Na}$ região de Ribeirão Preto, foram coletados perfis de quatro unidades diferentes: Li-bas (P-1059), TE (P-1103), LRe P-1099) e LRd (P1057), cujos materiais de origem são derivados de rochas básicas; os teores de zinco total dos quatro perfis são muito diferentes entre si, e são consequiência dos processos de alteração a que as rochas foram submetidas.

Os solos derivados de sedimentos modernos arenosos são os que apresentam o mais baixo teor médio de zinco total. A pobreza em zinco, dos solos arenosos, já havia sido constatada por Vinogradov (20) e Wahhab \& Bhatti (21); o baixo teor em zinco dos solos derivados de sedimentos modernos arenosos decorre do fato de o material de origem, já retrabalhado, ter sua fração grosseira essencialmente constituída de quartzo e não apresentar minerais ricos em zinco (13).

Observando os valores do quadro 1 verifica-se que a terra roxa estruturada apresenta uma diminuição dos teores de zinco total do horizonte A para o B. A diminuição dos teores de zinco com a profundidade já havia sido assinalada por outros autores $(\mathbf{1 0}, \mathbf{2 0})$. Observou-se a existência de um coeficiente de correlação $\mathrm{r}=0,95^{* *}$ entre os teores de areia e zinco, fato que pode ser explicado pela fração grosseira da terra roxa estruturada apresentar ilmenita e magnetita, minerais ricos em zinco (13, 20). O latossolo roxo apresenta o teor de zinco do horizonte $A$ semelhante ao do horizonte B, explicável pela semelhança de composição entre os dois horizontes. Os podzolizados de Lins e Marília, var. Marília, o latossolo vermelho-escuro fase arenosa e o latossolo vermelho-amarelo húmico apresentam um aumento do teor de zinco do horizonte $\mathrm{A}$ para o B, fato já constatado em solos da União Sul-africana por Stanton e Burger (14).

Foi calculada a correlação entre os teores de zinco e os de $\mathrm{Fe}_{2} \mathrm{O}_{3}$, extraídos do solo pelo ataque sulfúrico (19), obtendo-se $\mathrm{r}=0,79^{* *}$; outros autores $(8,15)$ também obtiveram boa correlação entre os teores de zinco $e$ os de 6 xidos de ferro. 
Foi calculada a correlação entre os teores de zinco e os de matéria orgânica, expressa em carbono, não tendo sido obtida correlação satisfatória, já que $r=0,20$. Hervieu e Nalovic (5) e Tucker \& Kurtz (17) também não encontraram boa correlação entre os teores de zinco e os de carbono. ,

QUADRO 1. - Teore mbdion, ponderados, de zinco total em perfia das princlpais unidades de colos do Sto Paulo

\begin{tabular}{|c|c|c|c|c|}
\hline UNIDADE & Perfil & Forizonte & Espectura & Zinco \\
\hline \multirow{3}{*}{ 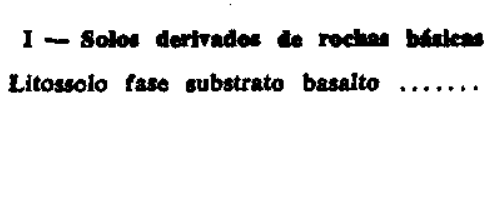 } & & & co & pom \\
\hline & P.1059 & $\stackrel{A}{\mathbf{C}}$ & $\begin{array}{l}13 \\
12 \\
55\end{array}$ & $\begin{array}{l}315,3 \\
282,7 \\
206,3\end{array}$ \\
\hline & T.5686 & $\mathbf{A}$ & 20 & $\begin{array}{l}211,3 \\
202,3\end{array}$ \\
\hline \multirow[t]{2}{*}{ Terre roxa estruturada $\ldots \ldots \ldots \ldots \ldots$} & $\mathbf{P}+1103$ & $\stackrel{\mathbf{A}}{\mathbf{B}}$ & $\begin{array}{l}30 \\
96 \\
29\end{array}$ & $\begin{array}{l}247,6 \\
173,5 \\
164,0\end{array}$ \\
\hline & P-1114 & $\stackrel{\mathbf{A}}{\mathbf{B}}$ & $\begin{array}{r}15 \\
255 \\
100\end{array}$ & $\begin{array}{l}161,3 \\
130,7 \\
131,7\end{array}$ \\
\hline \multirow[t]{2}{*}{ Latossolo roxo eutrofleo $\ldots \ldots \ldots \ldots \ldots$} & P-1099 & $\stackrel{\hat{\mathbf{A}}}{\mathbf{T}}$ & $\begin{array}{r}41 \\
159 \\
100\end{array}$ & $\begin{array}{l}205,3 \\
214,9 \\
218,0\end{array}$ \\
\hline & P-1118 & $\underset{\mathbf{A}}{\mathbf{A}}$ & $\begin{array}{r}34 \\
236 \\
100\end{array}$ & $\begin{array}{l}150,8 \\
140,9 \\
164,5\end{array}$ \\
\hline \multirow[t]{2}{*}{ Latossoto roxo distroftco $\ldots \ldots \ldots \ldots \ldots$} & P-10s7 & $\stackrel{\mathbf{A}}{\mathbf{T}}$ & $\begin{array}{r}28 \\
172 \\
300\end{array}$ & $\begin{array}{l}87,0 \\
87,5 \\
90,7\end{array}$ \\
\hline & P-1065 & $\underset{\mathbf{T}}{\mathbf{A}}$ & $\begin{array}{r}43 \\
117 \\
100\end{array}$ & $\begin{array}{l}178,4 \\
178,4 \\
174,5\end{array}$ \\
\hline \multicolumn{5}{|l|}{$\begin{array}{c}\text { II - solos derivados de matering: } \\
\text { nlovials e coluvials }\end{array}$} \\
\hline \multirow[t]{2}{*}{ Hidromórfico $\quad \ldots \ldots \ldots \ldots \ldots \ldots \ldots \ldots$} & P-1061 & $\hat{C_{g}}$ & $\begin{array}{r}15 \\
165\end{array}$ & $\mathbf{3 3 , 0}$ \\
\hline & P.1062 & $\hat{\mathbf{C}_{8}}$ & 25 & $\begin{array}{r}84,2 \\
100,1\end{array}$ \\
\hline \multicolumn{5}{|l|}{$\begin{array}{l}\text { III - Solon derivados de redinentos } \\
\text { modernos }\end{array}$} \\
\hline \multirow[t]{2}{*}{ Latossolo vermelho-escuro orto $\ldots \ldots \ldots$} & P.1090 & $\underset{\mathbf{A}}{\mathbf{A}}$ & $\begin{array}{r}36 \\
144 \\
320\end{array}$ & $\begin{array}{l}61,8 \\
55,8 \\
67,5\end{array}$ \\
\hline & P-1115 & $\stackrel{\mathbf{A}}{\mathbf{B}}$ & $\begin{array}{r}20 \\
310 \\
100\end{array}$ & $\begin{array}{l}65,2 \\
50,7 \\
49,5\end{array}$ \\
\hline Latossolo vermelho-amarelo orto $\ldots \ldots$ & P-1031 & $\begin{array}{l}\mathbf{A} \\
\stackrel{B}{C} \\
\mathbf{R}\end{array}$ & $\begin{array}{r}32 \\
328 \\
540\end{array}$ & $\begin{array}{l}60,4 \\
41,9 \\
51,9 \\
57,0\end{array}$ \\
\hline
\end{tabular}

- $\mathbf{T}=$ Tradagem. 
QUADRO 1. - (Continuagito)

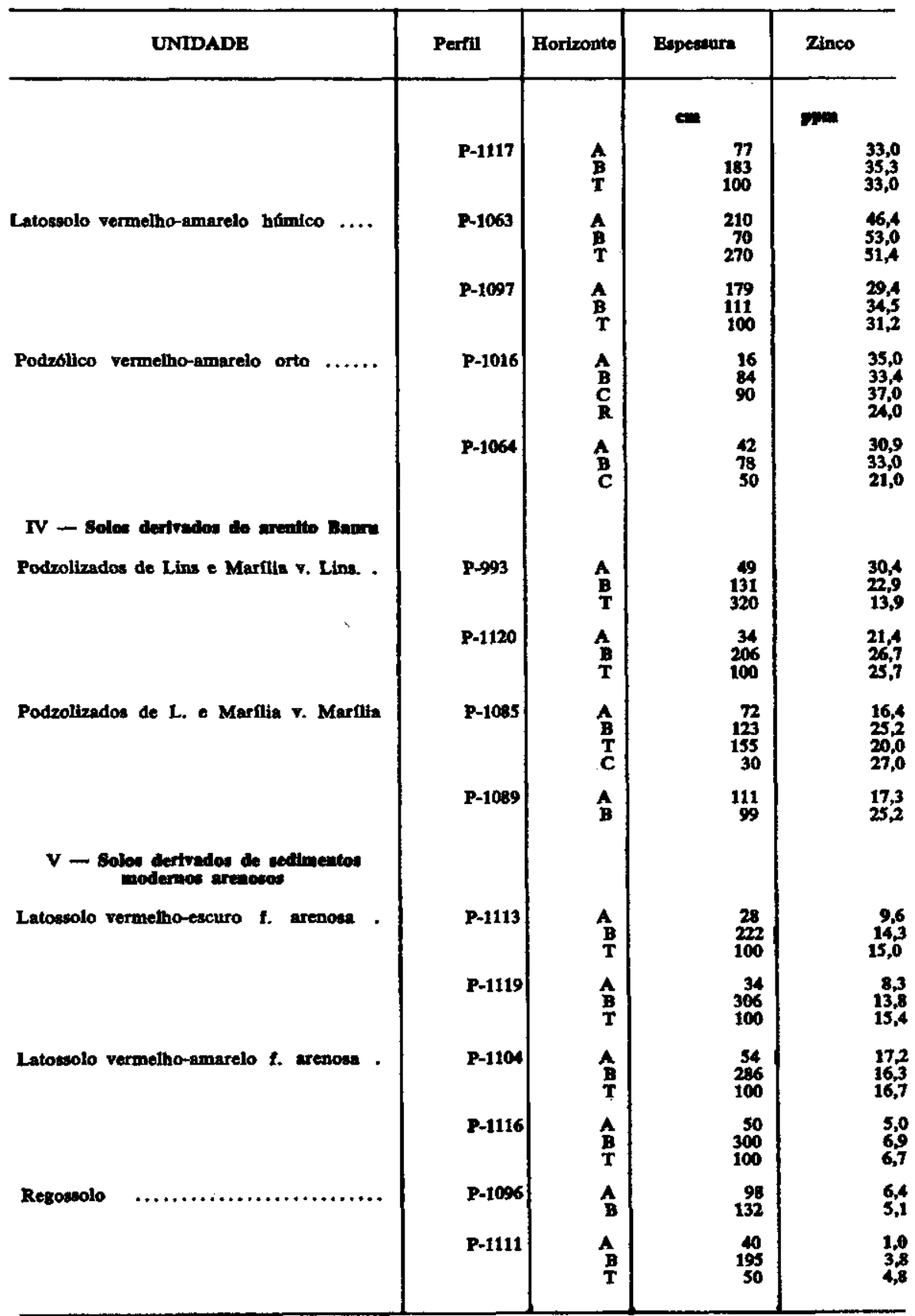




\title{
4 - CONCLUSOES
}

a) Os teores de zinco total dos sclos são primordialmente condicionados pelos teores de zinco dos materiais de origem. Os solos derivados de rochas básicas são os mais ricos em zinco, e os derivados de sedimentos modernos arenosos os mais pobres.

b) Numa mesma região geográfica, solos derivados de rochas básicas apresentam teores de zinco total diferentes, conseqüência dos processos de alteração a que as rochas foram submetidas.

c) A terra roxa estruturada apresenta uma diminuição do teor de zinco do horizonte A para o B; os latossolo vermelho-escuro fase arenosa, podzolizados de Lins e Marília, var. Marília, e latossolo vermelho-amarelo húmico apresentam aumento do teor de zinco do horizonte $\mathbf{A}$ para o B.

d) $\mathrm{O}$ teor de óxido de ferro do solo foi a característica que melhor se correlacionou com os teores de zinco total $\left(r=0,79^{* *}\right)$.

\author{
ZINC IN BOILS OF THE STATE OF SAO PAULO \\ 1 - TOTAL ZINC
}

\section{SUMMARY}

Determinations of total zinc, extracted with $\mathrm{HF}-\mathrm{HClO}_{4}$, were carrled out in 227 samples of 28 profiles of 14 soil units of the State of 8a.o Paulo, using the atomic absorption spectrophotometry.

The amount of zinc found in the different soils was mainly determined by the zinc content of the soll forming material.

In soils derived from basic igneous rocks, those richest in zinc, the weighted average contents of their A hortzons were between 87 and $315 \mathrm{ppm}$; in those derived from alluvial and coluvial materials the contents were 53 and $84 \mathrm{ppm}$; In those derived from modern sedilments the contents were batween 29 and 65 ppm; In those dertved from Bauru sandstone the contents were between 16 and $30 \mathrm{ppm}$ and in those derived from modern sandy sediments, the contents were between 1 and $17 \mathrm{ppm}$.

A significant correlation $\left(r=0,79^{* *}\right)$ was determined between the $\mathrm{Fe}_{2} \mathrm{O}_{3}$ and the total ginc contents in the studied solls.

\section{MTERATURA CITADA}

1. AITAN, J, E. The determination of zinc in agricultural materials by atomic absorption spectroscopy. Analyst 86:530-534, 1961.

3. BRADFORD, G. R.; ARKLEY, R. J. \& BAIR, F. K. Total contents of nine mineral elements in fifty selected Benchmark soll profiles oí Californla. Hugardia 38:541-556, 1967. 
3. FRAGoso, M. A. C. Microelementos em solos de Angola. Lisboa, Junta de Investigaçöes do Ultramar, 1859. 238p.

4. HANNA, W. J. Methods for chemical analysis of soils. In: BEAR, F. E., ed. Chemtstry of the soll. New York, Reinhold, 1967. p.474-502.

5. HMRVIEU, J. \& NALOVYC, Lj. Dosage des éléments cobalt, nickel, cuivre et zinc et leur distribution dans quelques types de sols de Madagascar. Cah. ORSTOM, ser. Ped. 3:237-265, 1065.

6. HIBBARD, P. L. The chemical status of zinc in the soll with methods of analysis. Hilgardia 13:1-29, 1940.

7. KHOKHLOVA, T, I. Content and distribution of microelements in the soils of the Kuznetsh forest steppe. Sov. Soil Scl. 1:47-68, 1967.

8. LE RICHE, H. H. \& WEIR, A. H. A method of studying trace elements in soil fractions. J. Boil Sci. 14:225-236, 1963.

9. NAIR, G. G. K. \& METHA, B. V. Status of zinc in solls of Western India. Soll Scl. 87:155-160, 1959.

10. OERTEL, A. C. Relation between trace elements concentration in solls and parent material. J. Soil Scl. 12:119-128, 1961.

11. RANDHAWA, N. S. \& KANWAR, J. S. Zinc, copper and cobsit status of Punjab solls. Soll Sc1. 98:403-407, 1964.

12. SANTANA, C. L. L. Formas totales y disponibles de cinc, cobre, maganeso, hierro $y$ mollbdeno en suelos de la region cacsotera de Bahia, Brasil. Turrialba, IICA, 1971. 112fls. (Tesis de Grado de Magister Scientiae.)

13. BeRviço NACIONAL DE PESQUISAs AGRONOMICAS. Comissio de Bolos. Levantamento de reconhecimento dos solos do Estado de Săo Paulo. Rio de Janeiro, Ministério ds Agricultura, 1960, 634p. (Bol. 12)

14. BTANTON, D. A. \& BURGER, R. du T. Studies on zinc in selected Orange Free State soils. 1 - An assessment of the zinc status of selected surface solis. S. Afr. J. agric. Bcl. 9:601-616, 1966.

15. Studies on zinc in selected Orange Free State solls. 2 - Distribution of zinc in selected soil profiles and in particle size fractions. 8. Afr. J. agric. Sci. 9:809-821, 1966.

16. THORNE, D. W.; LAWS, W. D. \& WALLACE, A. Zine relationships of some Utah solls. Boll Bci. 54:463-468, 1942.

17. TUCKER, T. C. \& KURTZ, I. T. A comparison of several chemtcal methods with the bio-assay procedure for extracting zinc from soll. Proc. Boll scl. Soc. Am. 19:477-481, 1955.

i8. Valadares, J. M. A. B. O ztnco em solos do Fistado de Bro Paulo. Piracicaba, Escola Buperlor de Agricultura "Luiz de Quelroz", 1972. 72fls. (Tese de doutoramento)

19. VETTORI, L. Métodos de análise de solo. Rlo de Janelro, Equipe de Pedologia e Fertilidade do Solo, 1869. 24p. (Bol. 7)

20. VINOGRADOV, A. P. The geochemistry of rare and dispersed chemical elements in soils. New York, Consultants, 1959. 209p.

21. WAHHAB, A. \& BHATTI, H. M. Trace element status of some west Pakistan solls. Soll 8cl. 86:319-323, 1956.

22. WOLTZ, S.; TOTH, S. J. \& BEAR, F. E. Zinc status of New Jersey soils. Soll Sci. 76:115-122, 1953.

23. ZYRIN, N. G. Distribution and variation of the content of micro elements in the solls of Russtan plain. Sov. Soll Scl. 7:933-942, 1968. 